\title{
Impact of Exclusive Bus Lanes on Traffic Performance in Urban Areas
}

\author{
Akmal Abdelfatah ${ }^{1}$, Amro R. Abdulwahid ${ }^{1}$ \\ ${ }^{1}$ American University of Sharjah \\ Civil Engineering Department, P.O. Box 26666, Sharjah, UAE \\ akmal@aus.edu
}

\begin{abstract}
With the anticipated growth rates within cities in the UAE, there is a need for an efficient public transportation system including busses. One of the possible approaches to improve the bus system performance in the UAE is the use of exclusive bus lanes (XBLs). This study investigates the impact of XBLs on urban road network performance under different traffic conditions using the micro-simulation software, VISSIM. It considers different parameters such as demand-to-capacity ratio D/C, traffic turning percentages, and bus headway and direction. Results show that the XBLs are effective at $\mathrm{D} / \mathrm{C}$ ratio of 0.80 or more. They also indicate that the turning percentages at the intersections have a significant impact on the XBLs performance. The XBLs were effective for the buses turning left for $\mathrm{D} / \mathrm{C}$ ratio of 1.15 of the main road. Furthermore, the performance of vehicles in adjacent lanes deteriorates after the implementation of XBLs for all $\mathrm{D} / \mathrm{C}$ ratios and the average deterioration percentages of vehicles' travel time, intersection delay, and average speed are $+5 \%,+11 \%$, and $-5 \%$, respectively.
\end{abstract}

Keywords: Public transportation, Exclusive bus lanes, Bus performance, Mode choice.

\section{Introduction}

In recent years, most of the cities in UAE, especially Sharjah, have been experiencing a significant increase in private vehicle use and slow development of infrastructure. As a result, the problem of urban traffic congestion has become a serious phenomenon. One of the main reasons that led to this problem is the limited growth of the transportation system supply which does not match the increase in travel demand. Simply, enhancing the road capacity by adding extra lanes or adding some infrastructures (bridges or tunnels) cannot satisfy the rapid growth of travel demand. Changes in land use and travel behavior encourage the use of private vehicles. Enhancing the infrastructure of a transportation system as intensive augmentation is usually expensive. Therefore, alternative solutions to mitigate traffic congestion are needed. One of the common approaches to reduce traffic congestion is to increase the mode share for public transportation, which can be achieved through some system modifications, such as transit signal priority and XBLs. Such system modifications may help in reducing the number of vehicles on the road and reducing the total travel time in the urban road network [1,2].

This research focuses on the use of XBLs as one of the most widely-used applications to improve the bus system performance. An XBL is a designated lane from the road to be used exclusively by public buses.

Exclusive bus lanes became part of the advanced sustainable multimodal transportation systems, in many cities around the world, and are considered an efficient and effective way to address urban congestion problems. In addition to that, XBLs are regarded as an effective approach to mitigate urban traffic congestion and reduce air pollution, as they result in less road space per capita and higher average occupancy per vehicle leading to a higher efficiency of the road network. Bus service quality in terms of travel time, delay, and average speed are well secured by XBLs in most cases.

\section{Literature Review}

The effects of implementing XBLs on urban traffic performance are frequently researched by scholars. Several studies and papers have been published to investigate before and after studies. The results tend to be mixed between unsuccessful and successful implementation of XBLs. Some researchers concluded that the XBL had a negative impact for both automobile and bus movement because of the lack of enforcement, many passenger cars were suing the XBLs [3,4]. However, several studies showed that the XBLs have positive impact on the performance of the buses' travel time, delay and average speed [5 - 8]. Other researchers discussed the possibility of allowing taxis and HOVs to use XBLs to reduce the traffic congestions on adjacent lanes after the implementation of XBLs especially at high level of congestions [9, 10]. 
Levinson and Sanders [11] developed a person delay model that examines the feasibility and practicability of implementing an XBL on freeway bus lanes in urban areas. The model helped to determine the number of buses needed to justify adding an XBL and represents a tool to allow urban transportation planners to determine the feasibility of XBL operations on urban freeways. Similarly, Pogun and Satir [12] conducted a study to show the development and investigation of the alternative dispatching and route policies for XBLs. The system was categorized by the number of passengers generated and shows the geometric features of the lane. In order to evaluate the new dispatching and routing polices, a micro-simulation model, representing the operational conditions, was developed. Also, the model introduced alternative dispatching and routing policies.

Alpern and Gersten [13] conducted a study to evaluate the use of XBLs in New Jersey. Freeway simulation software (FREQ8PL) was utilized to investigate the feasibility of the proposed XBLs. Optimizing the use of bottleneck capacity has been emphasized as one of the results. It also showed that the priority lane must start before the end of the queue of other vehicles.

Currie et al. [14] suggested a reasonable scope of work for roadway space reallocation related to transit priority. A simulation model was applied to identify the performance measures of transit priority. The results revealed the important benefits the buses gained in terms of less travel time, especially at high traffic volumes after the implementation of the bus lane. In another study [15], they introduced a methodology to evaluate trade-offs in the use of the limited road space in Melbourne, Australia for new bus and tram priority projects. The outcomes indicate that the priority rule is viable as low proportion of the results showed positive net economic gains after introducing bus schemes. Also, the public bus priority is more viable and has higher net positive economic returns when the bus has a high level of frequency and the traffic volume is low.

Mori et al. [16] used a simulation model called NETSTREAM to assess the use of XBLs in Nagoya, Japan. After the implementation of XBLs, the travel time decreased from 30 to 26 minutes which resulted in almost a $13 \%$ improvement. Chen et al. [17] carried out a study to examine the effect of XBLs and transit signal priority (TSP) on bus rapid transit (BRT) in China. A micro-simulation analysis was created based on extensive field data collection. The analysis showed that XBLs and TSP have a significant impact on the operational performance of BRT if both are implemented simultaneously.

Arasan and Vedagiri [18] tested the effect of introducing XBLs on a highly heterogeneous traffic flow on urban roads using a computer micro-simulation model called HETEROSIM, in Indian cities. The effect of XBLs was measured in terms of reducing the speed of other categories of vehicles. The results indicated that if the XBL is implemented under highly heterogeneous traffic conditions, then the maximum allowable volume-to-capacity ratio that will guarantee a level of service (LOS) $\mathrm{C}$ for the traffic flow including all vehicles users, except the buses, is about 0.53. In a later study [19], they proposed a procedure to modify and adjust a micro-simulation model of heterogeneous traffic flow and to study the effect of implementing XBLs on urban roads. The outcomes of the study revealed the possibility to implement XBLs on specified urban roads, and to improve the level of service of the bus without having a great impact on the level of service of other modes of transportation under the prevailing traffic conditions. The study also concluded that the implementation of XBLs will enhance the level of service of the buses and this result may also lead to a mode shift from passenger vehicle to bus, for some users.

$\mathrm{Yu}$ and Kun [20] studied the effect of implementing XBLs by establishing an evaluation model to assess the traffic efficiency adaptability of bus lanes in Guangzhou, China. The results showed that the arrangement of XBLs will help to increase travel speed of public buses on the road section as well as improve passenger capacity, which is obviously much higher than vehicle capacity, and bring indirect benefits such as relieving traffic jams which will improve the traffic environment and reduce pollution. Similarly, Biao and Qing-fang [21] proposed an evaluation method to compare traffic efficiency before and after the implementation of XBL on an intersection. The microsimulation software VISSIM4.30 was used to model an intersection, in Changchun city, to verify the proposed method. The simulated results indicated significant improvements as the average bus delay was reduced by $31.6 \%$ and the travel speed increased by $45.2 \%$ from $8.4 \mathrm{~km} / \mathrm{h}$ to $12.2 \mathrm{~km} / \mathrm{h}$.

$\mathrm{Li}$ and $\mathrm{Ju}$ [22] evaluated the implementation of XBLs by applying a multimode dynamic traffic assignment (DTA) model. The outcomes showed that the XBLs have direct benefits to the network such as reducing total system time, total system cost, and total bus queues.

Dong et al. [23] proposed a model to study the impact of setting up XBLs in urban areas by examining the essential principles of service level improvement with the constraint of travel time reliability. The objective function 
was to minimize the setup cost of bus lanes. The model used a bus line in Singapore as a case study to validate the model. Xia et al. [24] performed a study to analyze the influence of XBLs on traffic operation at an intersection. A simulation model was used to analyze vehicle total delay, vehicle average delay, passenger total delay, and passenger average delay by assigning the bus lanes at different settings VISSIM software was utilized to simulate the traffic operation at an intersection in Changsha, China. The results indicated that bus performance was enhanced in terms of time, and the vehicle delay and passenger delay decreased after the implementation of XBLs at the intersection.

As the forgoing literature review shows, there is no conclusive evidence that XBLs are effective everywhere in reducing traffic congestion and travel time or increasing travel speed. However, insights are drawn from these studies to investigate how XBLs would impact the traffic flow performance on a typical intersection.

\section{Methodology}

A micro-simulation model using VISSIM was created to study the implementation of an XBL on a typical 4-leg intersection. Table 1 shows the geometric characteristics of the Typical Intersection Model. The Typical Intersection Model represents the main road traffic network and local traffic conditions based on the data acquired from Sharjah Road and Transportation Authority (SRTA) with a number of major assumptions such as no U-turn movement on the main road, no actuation from pedestrian, fixed signal timing because this is the typical type of signal in Sharjah, and fixed ratio of right turn. The purpose of using the Typical Intersection Model was to isolate the impact of individual traffic parameters.

Table 1: Geometric Characteristics of the Typical Intersection Model

\begin{tabular}{|c|c|c|c|c|}
\hline & North & South & East & West \\
\hline Lane width (m) & 3.65 & 3.65 & 3.65 & 3.65 \\
\hline Lane Length (m) & 350 & 350 & 350 & 1000 \\
\hline Median width (m) & 1.5 & 1.5 & 1.5 & 1.5 \\
\hline Through lanes (per approach) & 2 & 2 & 2 & 2 \\
\hline Left lanes (per approach) & 1 & 1 & 1 & 1 \\
\hline Share lanes (left + through) & 1 & 1 & 1 & 1 \\
\hline Storage length of left-turn (m) & 125 & 125 & 125 & 125 \\
\hline Right-turn lanes (per approach) & 1 & 1 & 1 & 1 \\
\hline Right-turn control type & Free & Free & Free & Free \\
\hline
\end{tabular}

The geometric characteristics of the Typical Intersection Model before and after the implementing of an XBL are shown in Figures 1. In the model, one from the existing traffic lanes is dedicated as the XBL. 

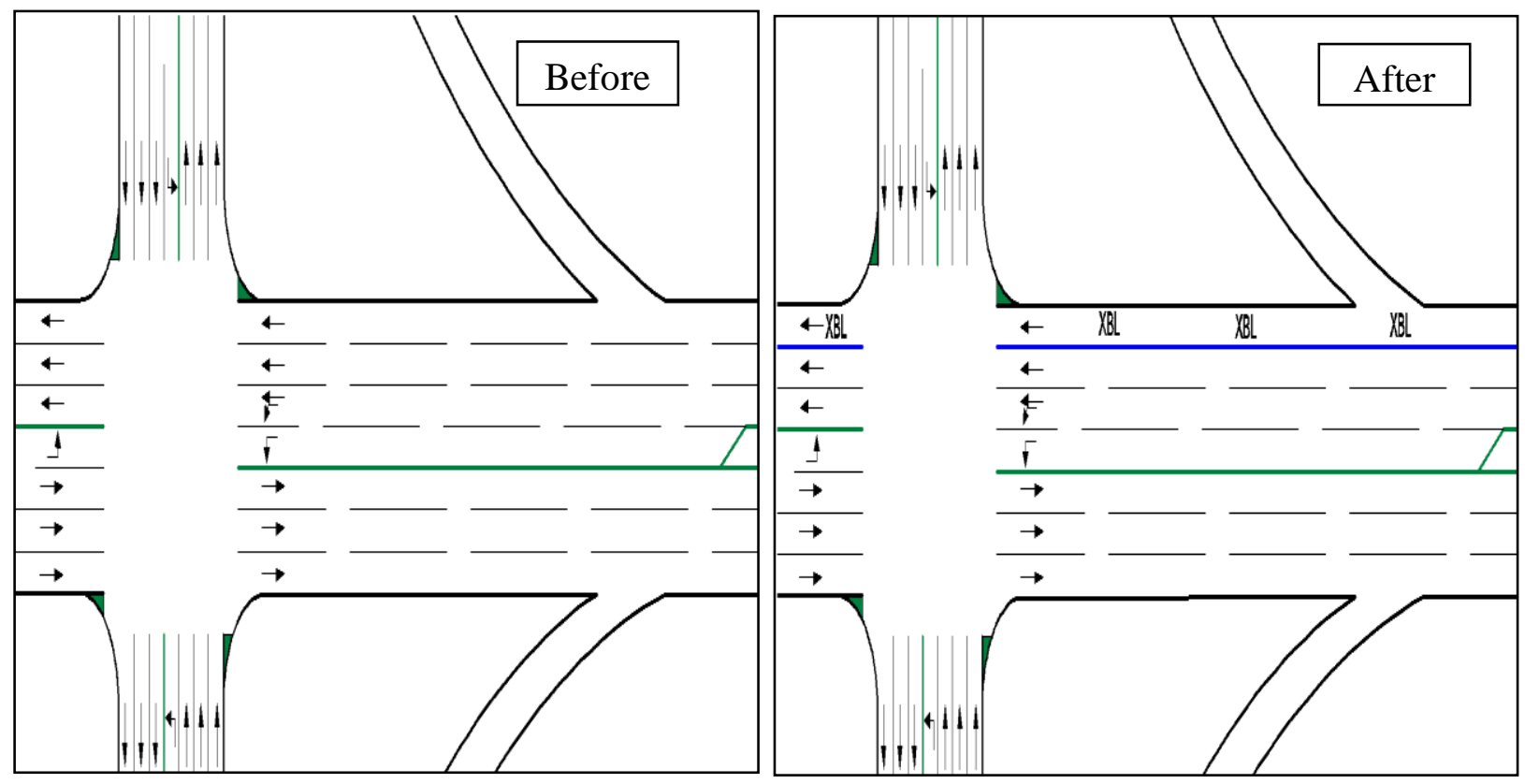

Fig. 1: Geometric Details of the Typical Intersection Model before Implementing the XBL to the Left and After Implementing the XBL to the Right.

VISSIM is a microscopic, time step, and behavior based simulation model of urban traffic and public transit operations. It visualizes the problem in a very realistic and relatively accurate approach thus plays a very important role in decision making process. The software can be used to evaluate different alternatives based on a transportation engineering measures of effectiveness. In this paper, Vissim is used to evaluate the performance of the XBL in each scenario [25].

As shown in Figure 2, different parameters were considered in the analysis of the parametric study using the Typical Intersection Model, including four different $\mathrm{D} / \mathrm{C}$ ratios on the main road, four traffic turning percentages, two bus movements, four bus headways, and one bus stop location (mid-block). The ratios of demand-to-capacity of the main road were chosen to represent low, moderate, high, and very high traffic congestion levels. Different percentages were assumed for the through and left turn movements starting from (70\% Straight - 20\% left) to (40\% Straight - 50\% left) with a fixed ratio of $10 \%$ of the right turn. It was assumed that the bus may have two movements; the first one is through, in which the bus will continue through after the intersection. The second one is left, in which the bus will make a left turn at the intersection. Four bus line headways were studied to examine the travel time of the bus. The marginal headways were selected to be 5-minutes in the lower end and 20-minutes in the upper end. The 5-minute headway represents the smallest value implemented and the 20 minute headway represents the off-peak headway of the current bus operation in the parametric study. Furthermore, the effects of the bus stop were studied through one set of experiments that considers a mid-block bus stop, which is the standard location for bus stops in Sharjah. It should be noted that Figure 3 below illustrates the parameters for one path only, but the same parameters apply for the others paths as well.

In this study, a simulation period length of 1 hour was used to analyze the scenarios. To be more realistic, the network used 15 minutes of warm-up time to load vehicles into the network. A simulation period of 1 hour would allow the buses to complete a full trip. During the 15-minute warm-up period, no statistics are gathered. Each microsimulation run presents a random seed; thus each scenario runs five times, for five different seeds, to account for the randomness of traffic volumes in VISSIM, which is required for ensuring the validity and stability of the results.

A trimmed mean was calculated by excluding the largest and the smallest values from the results and taking the arithmetic mean of the remaining three values. The trimmed mean approach was used to reduce the effects of extreme values on the calculated mean. 


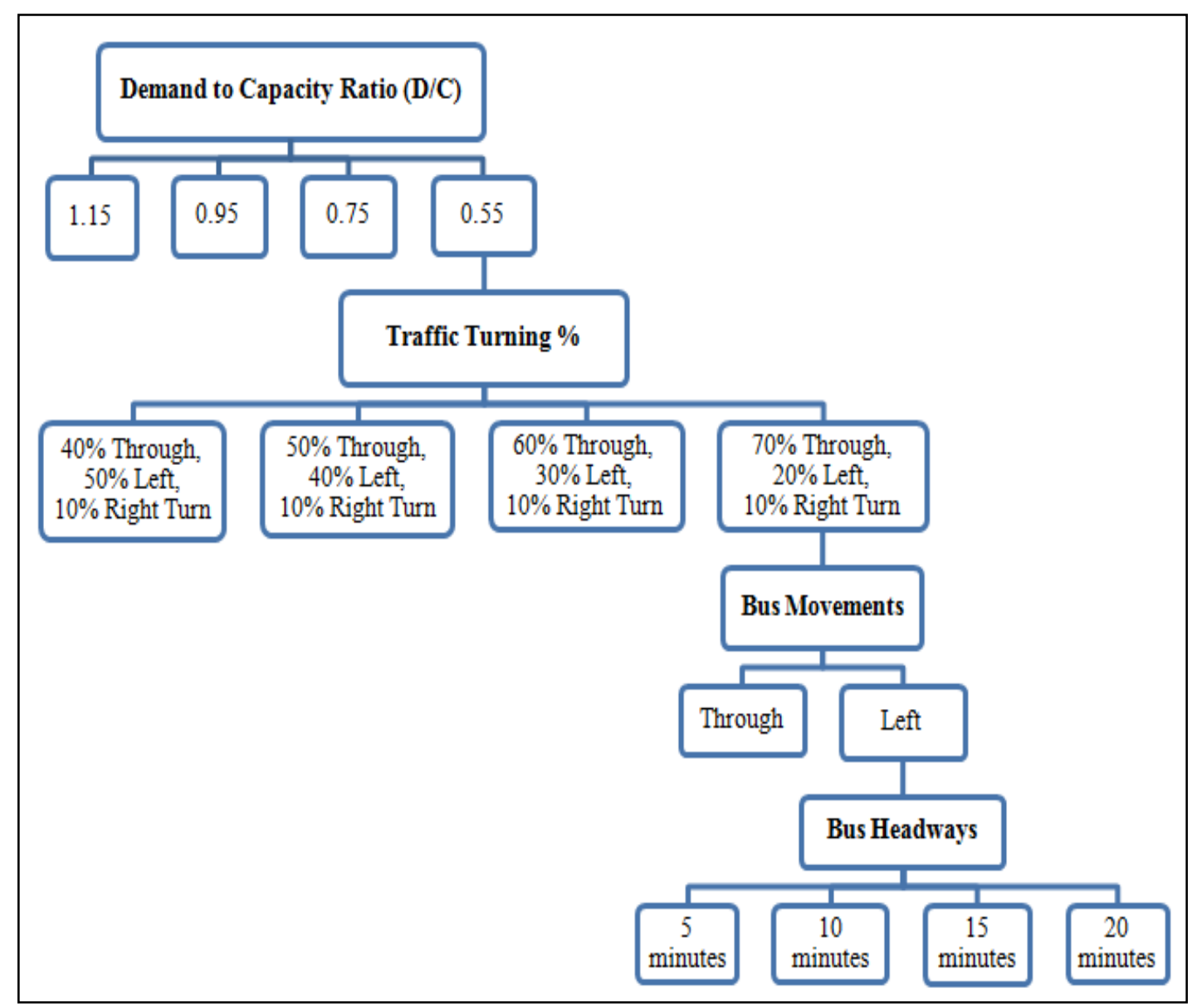

Fig. 2: Parameters used in the Typical Intersection Model.

\section{Results}

VISSIM simulation model has been utilized to evaluate different scenarios in order to determine the effect of different traffic parameters on the performance of an XBL in the traffic network. Many scenarios were simulated using VISSIM, and the impact of an XBL on the traffic network performance in terms of travel time, intersection delay, and average speed for the buses and the other vehicles operating with and without an XBL was analyzed individually for each scenario. Table 2 illustrates the considered parameters for this scenario. The travel time of buses along the main road corridor with and without the XBL under different D/C ratios on major traffic volume is shown in Figure 3. The buses' travel time, along the main road, increases as the $\mathrm{D} / \mathrm{C}$ ratio, for mixed traffic conditions on the main road, increases. Additionally, when considering the $\mathrm{XBL}$, the buses' travel time improves significantly as the buses will have a constant travel time regardless of the level of congestion on the main road. The effect of using the XBL on the travel time of the other vehicles on the main road is presented in Figure 4. For D/C ratios of 0.75 or less, the XBL has almost no effect on the other vehicles on the main road since the network is operating below its capacity, thus allowing other vehicles to maneuver freely without hindering the traffic. However for $\mathrm{D} / \mathrm{C}$ ratios of 0.95 or more, the network is fully congested and the other vehicles are trapped in traffic congestion. This is because the capacity of the road was reduced after taking one lane from the existing geometry and assigning it for the XBL.

Table 2: Considered Parameters for this Scenario

\begin{tabular}{|c|c|}
\hline Bus Direction & Through \\
\hline Demand to Capacity Ratios (D/C) & $0.55,0.75,0.95$, and 1.15 \\
\hline Traffic Turning \% & $40 \%$ through $-50 \%$ left $-10 \%$ right turn \\
\hline Bus Headways & 20 minutes \\
\hline
\end{tabular}




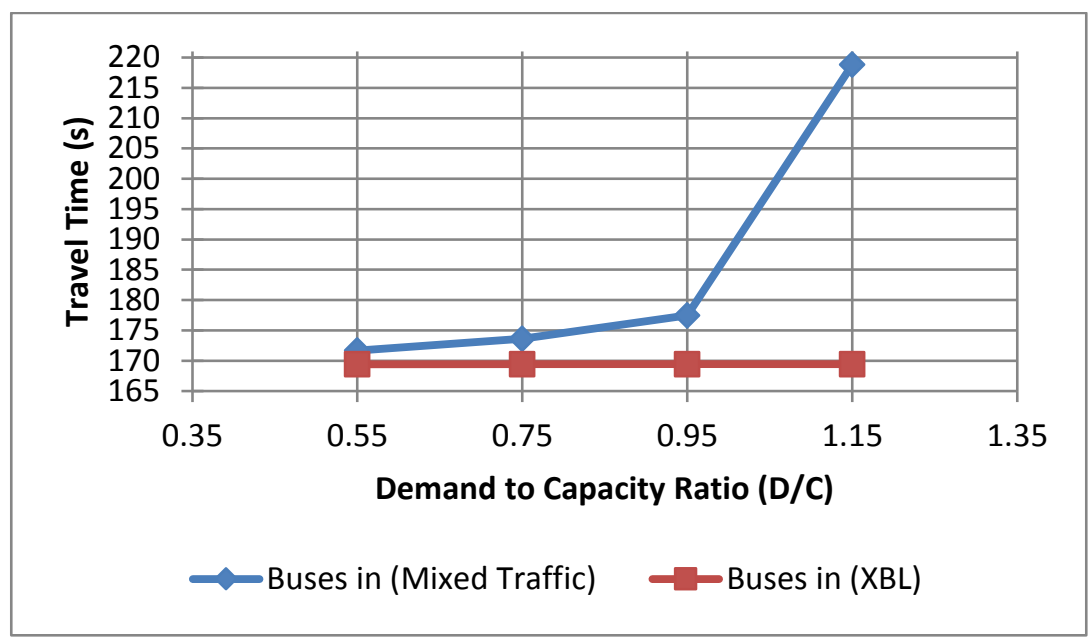

Fig. 3: Travel time for the buses along the main road corridor with and without XBL.

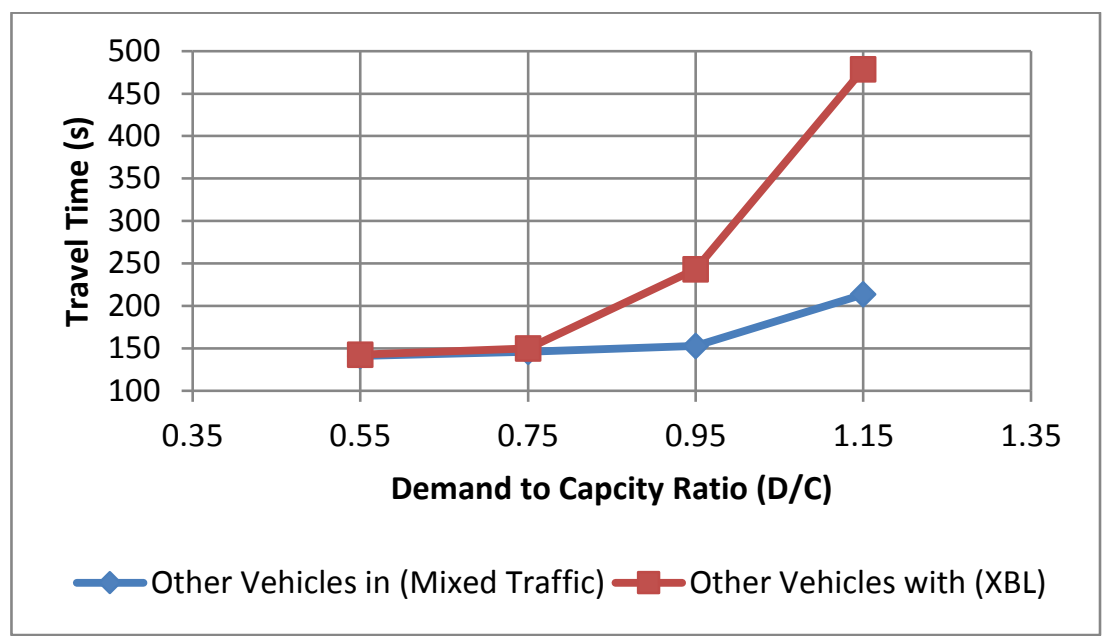

Fig. 4: The effect of using XBL on the travel times of the other vehicles.

Figure 5 illustrates the intersection delay for the buses along the main road corridor with and without the XBL under different $\mathrm{D} / \mathrm{C}$ ratios on major road volumes. Similar to the travel time, the bus delay increases with the increase in the traffic volume (or D/C ratio) in the mixed traffic conditions. After adding the XBL, the delay is almost constant. The effect of setting up the XBL on the delay of the other vehicles in adjacent lanes along the main road is shown in Figure 6. Similar to the travel time, for $\mathrm{D} / \mathrm{C}$ ratios of 0.75 or less, there is no effect of the XBL on the other vehicles. However, for high volume when the network reaches its maximum capacity (i.e. $\mathrm{D} / \mathrm{C} \geq 1.0$ ), the effect of the XBL is very clear as the intersection delay has increased almost to 3 times the intersection delay in the case of the other vehicles that operate in mixed traffic conditions. 


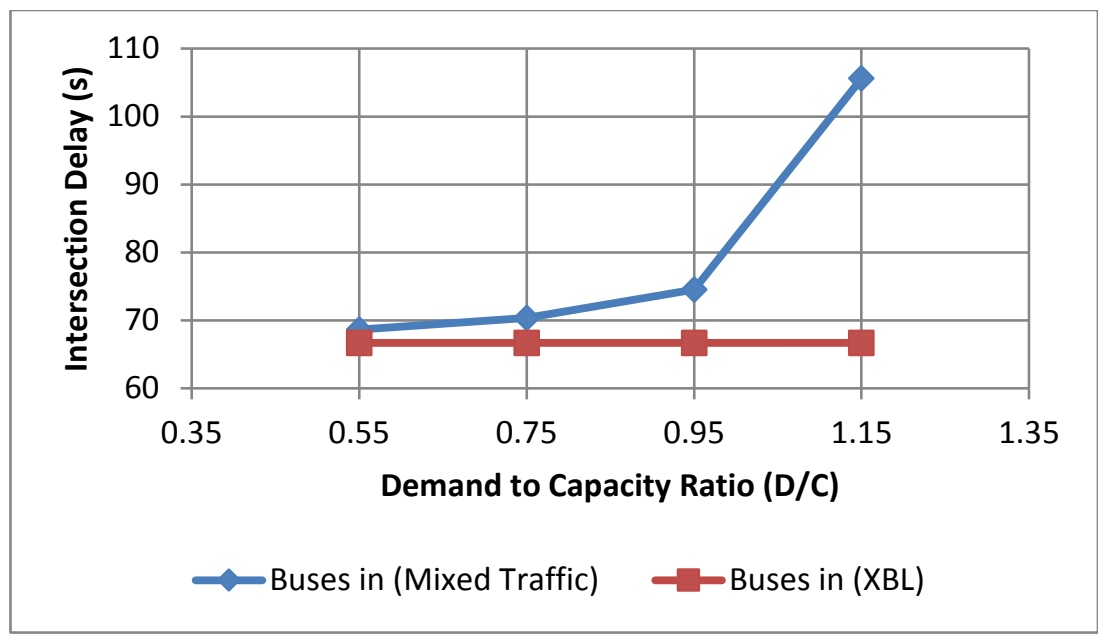

Fig. 5: Intersection delay for the buses along the main road with and without XBL.

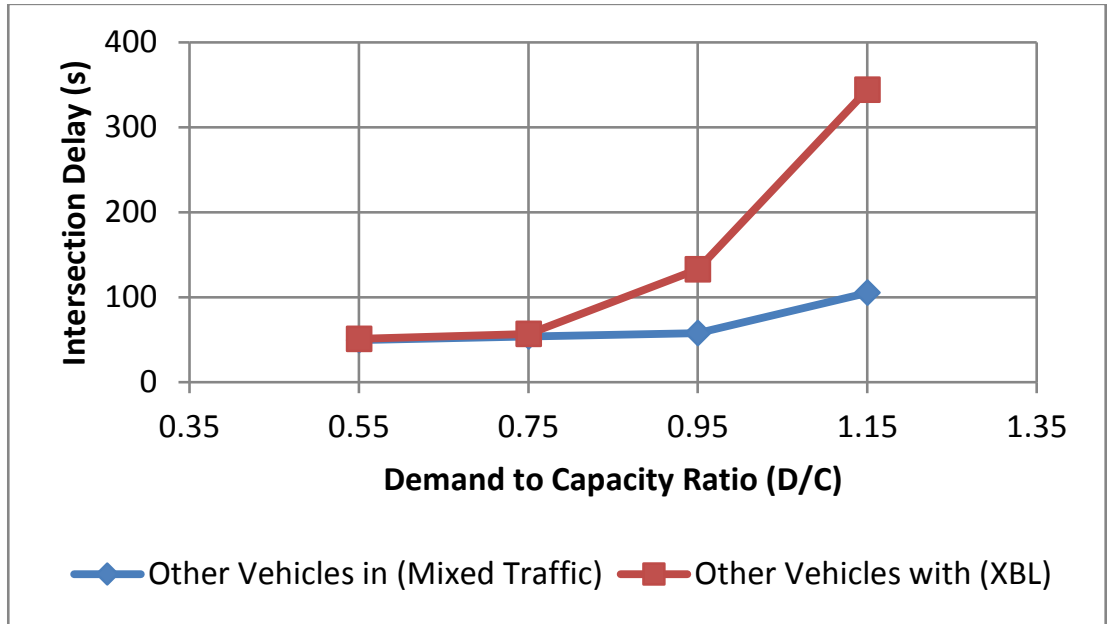

Fig. 6: The effect of XBL on other vehicles in adjacent lanes along the main road.

The average speed of the buses along the main road with and without the XBL under different D/C ratios. In mixed traffic conditions, the average speed of the buses along the main road decreases as the demand increases is shown in Figure 7. The deterioration in average speed of the buses reaches its maximum value when the network operates at or above its capacity (i.e. $\mathrm{D} / \mathrm{C} \geq 1.0$ ). However, the effect of the $\mathrm{XBL}$ on the average speed of the buses is very obvious as the buses maintain a constant speed along the whole segment of the road, where the XBL is implemented, because there is no interaction between the buses and other vehicles. Thus, indicate the importance of XBL to improve the performance of the buses' average speed at level of congestions.

On the other hand, the effect of installing the XBL on the average speed of the other vehicles in adjacent traffic lanes along the main road is introduced in Figure 8. The average speed of the other vehicles, in mixed traffic condition, experiences a significant drop when the $\mathrm{D} / \mathrm{C}$ ratio is equal to 0.95 or more, because the other vehicles try to maneuver from one lane to another and overtake other vehicles to reach their destination. While with the XBL, vehicles on the main road start to have a decrease in average speed for $\mathrm{D} / \mathrm{C}$ ratios of 0.75 or more, which shows the negative effect of implementing the XBL on the non-bus commuters in adjacent lanes. This drop occurs at a much higher rate because the available road space for the other vehicles, after reserving one lane for the XBL, is less than before. As a result, the other vehicles experience very low speed because of adding the XBL. 


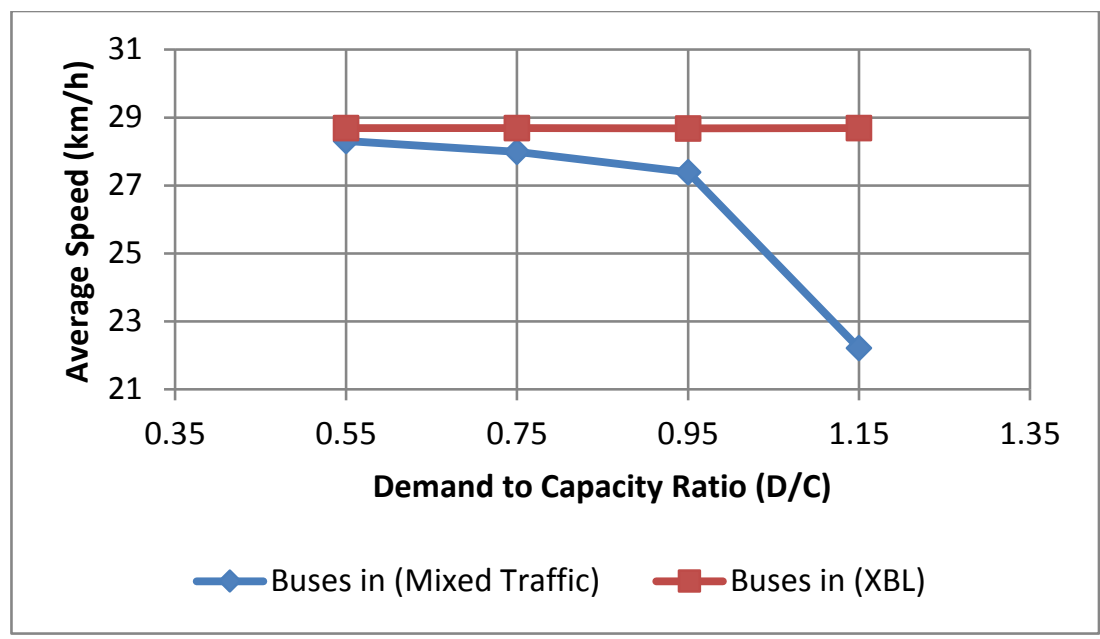

Fig. 7: Average speed for the buses along the main road with and without XBL.

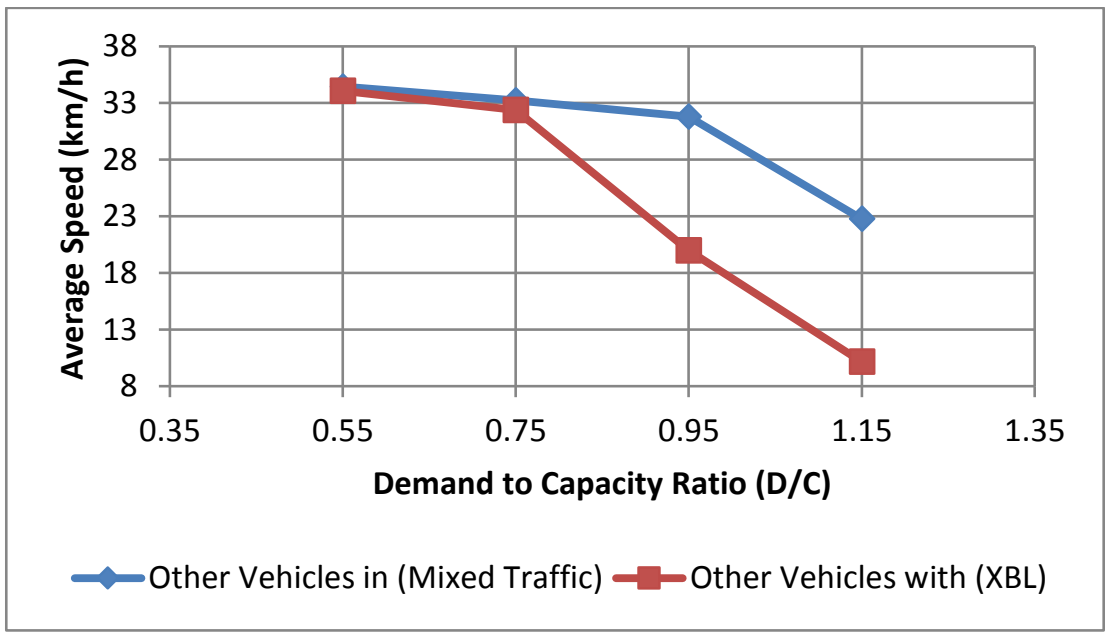

Fig. 8: Average speed of the other vehicles with and without XBL.

The improvement percentages of the buses and the deterioration percentages of the other vehicles in terms of travel time, intersection delay and average speed are shown in Table 3.

Table 3: The Performance of the Buses and the Other Vehicles before and after installing the XBL

\begin{tabular}{|c|c|c|c|c|c|c|c|}
\hline \multicolumn{2}{|c|}{ Intersection } & \multicolumn{5}{c|}{ Buses } & \multicolumn{3}{|c|}{ Other vehicles } \\
\hline \multirow{2}{*}{$\begin{array}{c}\text { D/C } \\
\text { Ratios }\end{array}$} & $\begin{array}{c}\text { Evaluation } \\
\text { Index }\end{array}$ & $\begin{array}{c}\text { Tr } \\
\text { avel Time } \\
(\mathbf{s})\end{array}$ & $\begin{array}{c}\text { Interse } \\
\text { ction Delay } \\
(\mathbf{s})\end{array}$ & $\begin{array}{c}\text { Avera } \\
\text { ge Speed } \\
(\mathbf{k m} / \mathbf{h})\end{array}$ & $\begin{array}{c}\text { Tra } \\
\text { vel Time } \\
(\mathbf{s})\end{array}$ & $\begin{array}{c}\text { Inters } \\
\text { ection Delay } \\
(\mathbf{s})\end{array}$ & $\begin{array}{c}\text { Avera } \\
\text { ge Speed } \\
(\mathbf{k m} / \mathbf{h})\end{array}$ \\
\hline \multirow{4}{*}{$\mathbf{0 . 5 5}$} & Before & 171.7 & 68.6 & 28.3 & 141.1 & 49.5 & 34.5 \\
\cline { 2 - 8 } & After & 169.4 & 66.7 & 28.7 & 142.7 & 51.0 & 34.1 \\
\cline { 2 - 8 } & Change & $\mathbf{1 . 3 \%}$ & $\mathbf{2 . 9 \%}$ & $\mathbf{1 . 3 \%}$ & $\mathbf{- 1 . 1 \%}$ & $\mathbf{- 3 . 1 \%}$ & $\mathbf{- 1 . 1 \%}$ \\
\hline \multirow{4}{*}{$\mathbf{0 . 7 5}$} & Before & 173.7 & 70.3 & 28.0 & 146.2 & 53.9 & 33.2 \\
\cline { 2 - 8 } & After & 169.4 & 66.7 & 28.7 & 150.2 & 56.9 & 32.4 \\
\cline { 2 - 8 } & Change & $\mathbf{2 . 4 \%}$ & $\mathbf{5 . 2 \%}$ & $\mathbf{2 . 5 \%}$ & $\mathbf{- 2 . 7 \%}$ & $\mathbf{- 5 . 5 \%}$ & $\mathbf{- 2 . 5 \%}$ \\
\hline \multirow{2}{*}{$\mathbf{0 . 9 5}$} & Before & 177.5 & 74.5 & 27.4 & 152.8 & 57.9 & 31.8 \\
\cline { 2 - 8 } & After & 169.5 & 66.7 & 28.7 & 243.3 & 132.9 & 20.0 \\
\hline
\end{tabular}




\begin{tabular}{|c|c|c|c|c|c|c|c|} 
& Change & $\mathbf{4 . 5 \%}$ & $\mathbf{1 0 . 5 \%}$ & $\mathbf{4 . 7 \%}$ & $\mathbf{- 5 9 . 2 \%}$ & $\mathbf{- 1 2 9 . 5 \%}$ & $\mathbf{- 3 7 . 2 \%}$ \\
\hline \multirow{3}{*}{1.15} & Before & 218.8 & 105.6 & 22.2 & 213.5 & 105.0 & 22.8 \\
\cline { 2 - 8 } & After & 169.4 & 66.7 & 28.7 & 478.8 & 344.0 & 10.2 \\
\cline { 2 - 8 } & Change & $\mathbf{2 2 . 6 \%}$ & $\mathbf{3 6 . 8 \%}$ & $\mathbf{2 9 . 1 \%}$ & $\mathbf{- 1 2 4 . 3 \%}$ & $\mathbf{- 2 2 7 . 6 \%}$ & $\mathbf{- 5 5 . 4 \%}$ \\
\hline
\end{tabular}

For medium volumes (i.e. $\mathrm{D} / \mathrm{C}$ ratios equal to 0.75 ), improvement percentages of the buses' travel time, intersection delay, and average speed are $2.4 \%, 5.2 \%$, and $2.5 \%$, respectively, while for high volumes like D/C ratios of 0.95 or more, the improvement percentages of the buses' travel time, intersection delay, and average speed are $4.5 \%, 10.5 \%$, and $4.7 \%$, respectively. Thus, this indicates that buses operating environment has been improved greatly after the implementation of the XBL. However, the other vehicles indexes had reduced in different degrees in all $\mathrm{D} / \mathrm{C}$ ratios, but with different magnitudes. For high level of demands like D/C ratios of 0.95 or more, the deterioration percentages of the other vehicles' travel time, intersection delay, and average speed are $-59.2 \%,-129.5 \%$, and $-37.2 \%$, respectively. Therefore, this shows the negative effect of the XBL on the performance of the other vehicles. While for medium level of demands such as D/C ratios of 0.75 or less, the deterioration percentages of the other vehicles' travel time, intersection delay, and average speed are $2.7 \%,-5.5 \%$, and $-2.5 \%$, respectively. This presents that the XBL has small impact on the performance of the other vehicles.

\section{Conclusions}

$\mathrm{XBL}$ was found to be effective at $(\mathrm{D} / \mathrm{C})$ ratios of 0.80 or more, because the travel time per bus in the $\mathrm{XBL}$ is lower than the travel time per vehicle with the XBL which indicates the effectiveness of the XBL to save travel time for the passengers at high levels of congestion. However, for $(\mathrm{D} / \mathrm{C})$ ratios of 0.75 or less, the travel time per bus in the XBL is higher than the travel time of the other vehicles moving in the adjacent lanes, which indicates that there is no need to operate the $\mathrm{XBL}$ at low levels of congestion. For the traffic turning percentages reaching the intersection (through and left), as the left turn movement percentage decreases and the through movement increase, the improvement percentages of the buses' travel time, intersection delay, and average speed increase and vice versa. For the buses turning left, the results showed that the XBL was not effective for $(\mathrm{D} / \mathrm{C})$ ratios of 0.95 or less on the main road corridor.

The application of the XBL can be based on time. In other words, the XBL can be used by other vehicles during offpeak hours. This will help in reducing the negative impacts of XBLs at low volumes $(\mathrm{D} / \mathrm{C}=0.55$ or 0.75$)$. The implementation for the XBL should avoid links in which the buses will turn left. This can be applied by allowing the buses that are turning left to use the common lanes instead of using the XBL.

\section{References}

[1] Yang, H., and W. Wang. An Innovative Dynamic Bus Lane System and Its Simulation-based Performance Investigation. in IEEE Intelligent Vehicles Symposium, 2009.

[2] Yao, J., F. Shi, Z. Zhou, and J. Qin. Combinatorial Optimization of Exclusive Bus Lanes and Bus Frequencies in MultiModal Transportation Network. Journal of Transportation Engineering, Vol. 138, no. 12, December 1, 2012, pp. 14221429.

[3] Erdman, J., and E.. Panuska. Exclusive Bus Lane. Traffic Engineering, Vol. 46, no. 7, 1976, pp. 28-33.

[4] Sarin, S., A.. S. Sarna, and B.. Sharme. Experience with Bus Lanes under Mixed Traffic. Institute of Transportation Engineers 53rd Annual Meeting, August, 1983.

[5] Cox, A. M. Reserved bus lanes in Dallas, Texas. Journal of Transportation Engineering, Vol. 101, no. 4, 1975, pp. 691-705.

[6] Rouphail, N. M. Operational Evaluation of Bus Priority Strategies. Transportation Research Record, 1984, pp. 30-34.

[7] Kim, H. J.. Performance of Bus Lanes in Seoul: Some Impacts and Suggestions. IATSS Research, Vol. 27, no. 2, 2003, pp. 36-45.

[8] Karim, S. N.A. The Effect of Bus Lane on Travel Time of Other Modes Using Floating Car Method. Proceedings of the Eastern Asia Society for Transportation Studies, Vol. 4, October, 2003, pp. 135-149.

[9] S. A. Shalaby and M. D. Soberman, "Effect of with flow bus lanes on bus travel times," Transp. Res. Rec, vol. 1433, p. 25-30, 1994. 
[10] M. Katsuragi, "Multilateral use of exclusive bus lanes in Kanazawa City," IEEE Conference on Intelligent Transportation Systems, Proceedings, ITSC, pp. 181-183, 1999.

[11] Levinson, H.. S., and D.. B. Sanders. Reserved bus lanes on urban freeways: a macro model. Transportation research record, Vol. 513, 1974.

[12] Pogun, G., and A. Satir. Alternative Bus Scheduling Policies for an Exclusive Bus Lane. Transportation Research, Part A: General, Vol. 20 A, no. 6, 1986, pp. 437-446.

[13] Alpern, B., and M.. Gersten. Uses of the FREQ8PL model to evaluate an exclusive bus - high - occupancy vehicle lane on New Jersey route 495. Transportation Research Record, no. 1132, 1987, pp. 42-52.

[14] Currie, G., M. Sarvi, and W.. Young. A Comparative Approach to Balanced Road Space Allocation in Relation to Transit Priority. in TRB Annual Meeting CD-ROM, Paper Number 04-3538, 2004.

[15] Currie, G., M. Sarvi, and W.. Young. A New Approach to Evaluating on-Road Public Transport Priority Projects: Balancing The Demand for Limited Road-Space. Transportation, Vol. 34, no. 4, 2007, pp. 413-428.

[16] Mori, H., H. Kitaoka, and E.. Teramoto. Traffic Simulation for Predicting Traffic Situations at Expo 2005. R\&D Review of Toyota CRDL, Vol. 41, no. 4, 2006, pp. 45-51.

[17] Chen, X.M., L. Yu, L. Yu, and S.X. Guo. Impacts of exclusive lanes and signal priority on bus rapid transit effectiveness. in International Conference on Transportation Engineering 2007, ICTE 2007, Chengdu, China, 2007.

[18] Arasan, V.. T., and P.. Vedagiri. Bus Priority on Roads Carrying Heterogeneous Traffic: a Study Using Computer Simulation. European Journal of Transport and Infrastructure Research, Vol. 8, no. 1, 2008, pp. 45-63.

[19] Arasan, V. T., and P. Vedagiri. Planning for dedicated bus lanes on roads carrying highly heterogeneous traffic. in 50th Annual Transportation Research Forum 2009, Portland, OR, United states, 2009.

[20] Yu, B., and X. Kun. Discussion About Evaluation Method of Traffic Efficiency Adaptability of Bus Lane. in Second International Conference on Intelligent Computation Technology and Automation, 2009.

[21] Qing-fang, Y., and Z. Biao. Impacts Evaluation of Setting Bus Lanes in Signalized Intersections. in International Conference on Transportation, Mechanical, and Electrical Engineering (TMEE), Changchun, China, 2011.

[22] Li, S., and Y. Ju. Evaluation of Bus-Exclusive Lanes. IEEE Transactions on Intelligent Transportation Systems, Vol. 10, no. 2, 2009, pp. $236-245$.

[23] Dong, Z., L. Qiang, and M. Lixin. Modeling on setting up bus lane in urban area with the constraint of travel time reliability. in International Conference on Management and Service Science, Wuhan, 2009.

[24] Xia, X., Z. He, J. Fang, and W. Zeng. The influence analysis of bus lane on traffic operation in intersection. in 12th COTA International Conference of Transportation Professionals: Multimodal Transportation Systems - Convenient, Safe, Cost-Effective, Efficient, CICTP 2012, Beijing, China, 2012.

[25] PTV. VISSIM 6.15 User's Manual. PTV AG, Karlsruhe, Germany, 2014. 